\title{
Tubeimoside-1 inhibits proliferation and induces apoptosis by increasing the Bax to Bcl-2 ratio and decreasing COX-2 expression in lung cancer A549 cells
}

\author{
YI ZHANG ${ }^{1}$, XIAOMAN XU ${ }^{2}$ and PING $\mathrm{HE}^{1}$ \\ Departments of ${ }^{1}$ Geriatrics, and ${ }^{2}$ Respiratory Medicine, The Shengjing Hospital \\ of China Medical University, Liaoning 110004, P.R. China \\ Received July 16, 2010; Accepted October 6, 2010
}

DOI: $10.3892 / \mathrm{mmr} .2010 .379$

\begin{abstract}
Plant materials are a great source of cancer chemotherapeutic agents. Tubeimoside-1 (TBMS1) is a triterpenoid saponin extracted from the tubers of Bolbostemma paniculatum (Maxim.) Franquet (Cucurbitaceae), a widely prescribed traditional Chinese medicinal plant that is used for its antiviral and anti-inflammatory properties. The present study was conducted to investigate the effects of TBMS1 on the growth and apoptosis of human lung cancer A549 cells. TBMS1 inhibited the proliferation of the cells in a doseand time-dependent manner. Apoptosis was confirmed by flow cytometry, fluorescence microscopy and transmission electron microscopy. TBMS1 treatment induced apoptosis by decreasing the expression of Bcl-2 and increasing the expression of Bax in the A549 cells. Inhibition of COX-2 was also observed after treating the cells with TBMS1. TBMS1 may prove to be a useful approach for the chemotherapy of lung cancer.
\end{abstract}

\section{Introduction}

Lung cancer is one of the most common human cancers and the leading cause of cancer-related death worldwide $(1,2)$. At present, the treatment of lung cancer mainly consists of surgery, radiotherapy and chemotherapy. However, the existing treatment is not adequate and has numerous side effects. The mortality of lung cancer remains high and the 5-year overall survival is less than $15 \%$ (3). The identification of more effective therapeutic approaches to treat lung cancer and other

Correspondence to: Dr Ping He, Department of Geriatrics, the Shengjing Hospital of China Medical University, Liaoning 110004, P.R. China

E-mail: cmu2h@hotmail.com

Abbreviations: TBMS1, tubeimoside-1

Key words: tubeimoside-1, apoptosis, A549 human lung cancer cell line malignancies is necessary. Recently, the use of plant materials as anti-cancer agents has gained a great deal of attention for its possible therapeutic qualities with minimal toxicity $(4,5)$.

Bolbostemma paniculatum (Maxim.) Franquet (Cucurbitaceae) is a traditional Chinese medicinal plant that was listed in the Supplement to the Compendium of Materia Medica, compiled in 1765, at the time of the Qing Dynasty. It has been used for a long time as a naturally occurring medicine in the treatment of numerous diseases and possesses well-documented antiviral, anti-inflammatory, anticancer and immunosuppressive activities (6-8). Tubeimoside-1 (TBMS1) (Fig. 1), a triterpenoid saponin whose sugar chains are connected by 3-hydroxy-3-methylglutaric acid to form a unique macrocyclic structure, was isolated from the tubers of Bolbostemma paniculatum $(9,10)$. Apoptosis plays a crucial role in developmental processes, the maintenance of homeostasis and the elimination of the damaged cells. Many plant anticancer agents cause the death of cancer cells through the induction of apoptosis $(11,12)$. TBMS1 has been found to induce cell apoptosis in several human carcinoma cell lines (13-16). However, the effects of TBMS1 on human lung cancer cells remain unclear.

In the present study, we investigated the effect of TBMS1 on the growth of human A549 cells and the molecular basis of its regulation of apoptosis. TBMS1-induced apoptosis was found to be accompanied by modulation of the Bcl-2 family, increased Bax protein levels and decreased Bcl-2 protein levels in A549 cells. Inhibition of COX-2 was also observed.

\section{Materials and methods}

Chemicals and reagents. TBMS1 (HPLC $\geq$ purity 98\%) was purchased from the National Institute for the Control of Pharmaceutical and Biological Products (Beijing, China). A 1-mM stock solution of TBMS1 was dissolved in PBS and stored at $-20^{\circ} \mathrm{C}$. RPMI-1640, penicillin, streptomycin and trypsin were purchased from Biological Industries (Kibutz Beit Haemek, Israel). Fetal bovine serum (FBS) was purchased from Solarbio Science and Technology (Beijing, China). 3-(4, 5-dimethyl thiazol-2yl)-2, 5-diphenyltetrazolium bromide (MTT), Hoechst 33342 and a dimethyl sulfoxide (DMSO) kit were purchased from Sigma-Aldrich (St. Louis, 


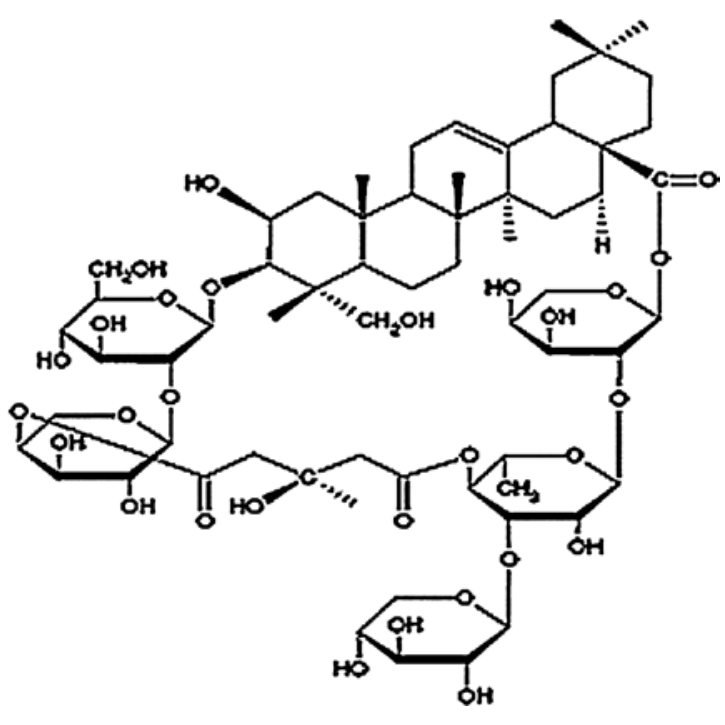

Figure 1. The structure of Tubeimoside-1.

MO, USA). An Annexin V-FITC and PI double staining kit were purchased from Key Gene (Nanjing, China). Antibodies against Bcl-2, Bax and COX-2 were purchased from Santa Cruz Biotechnology (Santa Cruz, CA, USA). Horseradish peroxidase-conjugated secondary antibody was obtained from Santa Cruz Biotechnology. All other chemicals were obtained from Sinopharm Chemical Reagent (Shenyang) Co., Ltd. (Shenyang, China).

Human lung cancer cell line A549. The human lung cancer cell line A549 was obtained from the China Center for Type Culture Collection (Wuhan, China) and cultured in RPMI1640 supplemented with $10 \%$ FBS, $100 \mathrm{U} / \mathrm{ml}$ penicillin and $100 \mu \mathrm{g} / \mathrm{ml}$ streptomycin at $37^{\circ} \mathrm{C}$ in a humidified atmosphere of $5 \% \mathrm{CO}_{2}$. The culture medium was changed every day. Cells for assays were detached by a solution of $0.25 \%$ trypsin and $0.02 \%$ EDTA.

Cell viability assay. Viability was assessed by the MTT [3-(4,5-dimethylthiazol-2-yl)-2-5-diphenyltetrazoliumbromide] assay. The A549 cells were plated at a density of $1 \times 10^{4}$ cells/ well in 96-well plates overnight, then treated with different concentrations of TBMS1 $(2,4,8,12$ and $16 \mu \mathrm{mol} / \mathrm{l})$. After exposure to TBMS1 for 24,48 or $72 \mathrm{~h}, 25 \mu \mathrm{l}$ of MTT solution ( $2 \mathrm{mg} / \mathrm{ml}$ in PBS) was added to each well, and the plates were incubated for an additional $4 \mathrm{~h}$ at $37^{\circ} \mathrm{C}$. Then, the medium was totally removed and $150 \mu 1$ of DMSO was added to each well to solubilize the formazan crystals formed in viable cells. Finally, the plates were shaken and the optical density was determined at $570 \mathrm{~nm}$ (OD570) using an ELISA plate reader (Model 550; Bio-Rad, USA).

Morphological analysis of apoptosis by fluorescence microscopy and transmission electron microscopy. The morphology of the apoptotic cells was detected by nuclear staining with Hoechst 33342. The A549 cells $\left(5 \times 10^{5}\right)$ were grown on coverslips placed in 6-well plates overnight, then treated with TBMS 1 ( 0 and $8 \mu \mathrm{mol} / \mathrm{l})$. After $24 \mathrm{~h}$, the cells were washed twice with cold PBS, fixed with cold methanol and acetic acid
$(3 / 1, v / v)$ at $4^{\circ} \mathrm{C}$ overnight, stained with Hoechst 33342 for 30 min in the dark, washed again in PBS and finally mounted in mounting medium (80\% glycerol in PBS). Processed cells were observed with a fluorescence microscope (Nikon, Japan).

Transmission electron microscopy (TEM) was used to observe the ultrastructure of the TBMS1-treated A549 cells. Briefly, the A549 cells were treated with TBMS1 (0 and $8 \mu \mathrm{mol} / \mathrm{l})$. After $24 \mathrm{~h}$, the cells were harvested and fixed in $2.5 \%$ glutaraldehyde at $4^{\circ} \mathrm{C}$ overnight. After removal of the primary fixative, cells were washed three times with MOPS buffer, post fixed in $1 \%$ osmium tetroxide $\left(\mathrm{OsO}_{4}\right)$, dehydrated in graded alcohol and embedded in epoxy resin. Ultra thin sections were double-stained with lead citrate/uranyl acetate before being examined by a JEM-100CX transmission electron microscope (Japan).

Annexin V/PI flow cytometric analysis. The number of apoptotic cell induced by TBMS1 was measured by flow cytometry using an Annexin V-FITC apoptosis kit. Briefly, following treatment with TBMS $1(0,4,8$ and $12 \mu \mathrm{mol} / \mathrm{l})$ for $24 \mathrm{~h}, 1 \times 10^{6}$ cells were harvested by centrifugation $(1,000 \mathrm{rpm} /$ min) and washed twice with cold PBS. The cell pellet was re-suspended in $1 \mathrm{X}$ binding buffer at a concentration of $1 \times 10^{6}$ cells $/ \mathrm{ml}$. Cell suspension $(100 \mu \mathrm{l})$ was transferred into an FCM tube. Annexin V-FITC (5 $\mu 1)$ and $10 \mu 1$ of PI were added to the cell suspension, followed by gentle vortexing. The cells were incubated at room temperature for $15 \mathrm{~min}$ in the dark. An additional $400 \mu 1$ of $1 \mathrm{X}$ binding buffer was added to each tube. The cells were analyzed using a FACScan flow cytometer and analyzed using Cell Quest software (Becton Dickinson, San Jose, CA, USA).

Western blot analysis. The expression of apoptosis-related proteins was evaluated by Western blotting. In brief, A549 cells $\left(1 \times 10^{7}\right)$ were treated with TBMS1 $(0,4,8$ and $12 \mu \mathrm{mol} / \mathrm{l})$ for $24 \mathrm{~h}$. The cells were then collected and washed twice with cold PBS, lysed in a lysis buffer (20 mM HEPES, pH 7.9, $20 \%$ glycerol, $200 \mathrm{mM} \mathrm{KCl}, 0.5 \mathrm{mM}$ EDTA, 0.5\% NP40, $0.5 \mathrm{mM}$ DTT and $1 \%$ protease inhibitor cocktail) and maintained on ice for $30 \mathrm{~min}$. The cell lysates were centrifuged at 12,000 rpm at $4^{\circ} \mathrm{C}$ for $20 \mathrm{~min}$, and the supernatants were stored at $-80^{\circ} \mathrm{C}$ until further use. Protein concentration was determined by the Bradford method. Supernatant samples containing $50 \mu \mathrm{g}$ of total protein were resolved on an SDS-PAGE gel depending on the target protein sizes. Next, proteins separated by SDS-PAGE were transferred to PVDF membranes for $1 \mathrm{~h}$ at $80 \mathrm{~V}$. Membranes were first blocked with 5\% non-fat dry milk at room temperature for $1 \mathrm{~h}$, followed by incubation with the primary antibodies Bcl-2, Bax and COX-2, respectively, at $4^{\circ} \mathrm{C}$ overnight. After being washed with TBST for $30 \mathrm{~min}$, the corresponding secondary antibody was added, followed by incubation at room temperature for $2 \mathrm{~h}$. The membrane was then washed for 30 min with TBST. Visualization was conducted using an ECL kit. $\beta$-actin was detected on the same membrane and used as a loading control.

Statistical analysis. Each experiment was conducted three times. Data were expressed as the mean $\pm \mathrm{SD}$. The statistical significance of correlations was assessed by ANOVA and 


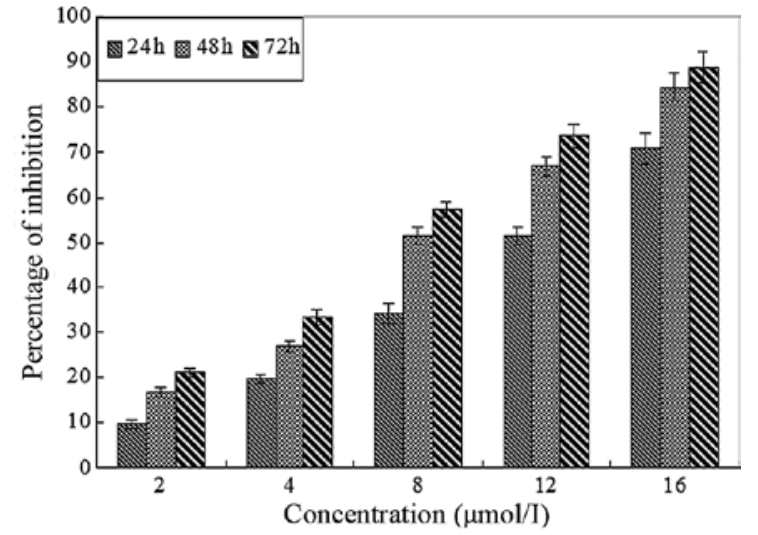

Figure 2. Proliferation inhibition effects of TBMS1 on human lung cancer A549 cells.

A

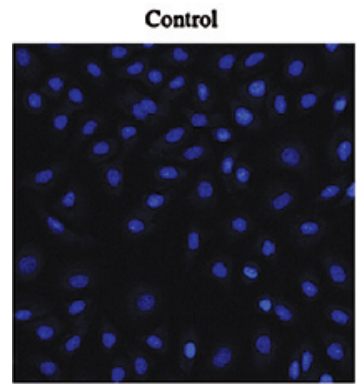

TBMS1 $8 \mu \mathrm{mol} / 1$

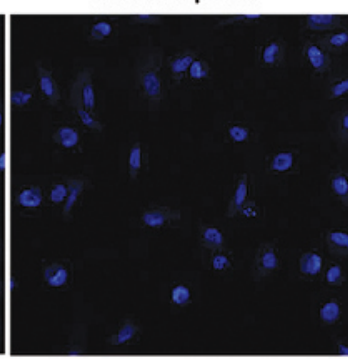

Morphological analysis by Hoechst 33342

B

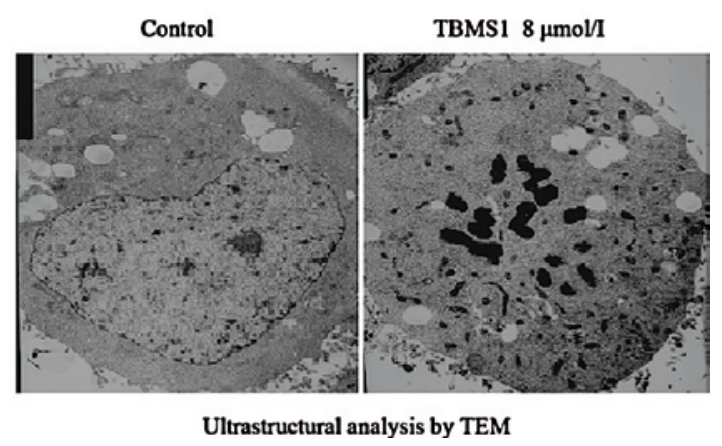

Figure 3. (A) Cell apoptosis observed by Hoechst 33342 staining. A549 cells treated with 0 and $8 \mu \mathrm{mol} / 1$ TBMS1 for $24 \mathrm{~h}$. Apoptotic cells exhibited chromatin condensation and nuclear fragmentation. (B) Cell ultrastructure changes observed by transmission electron microscopy (TEM). A549 cells treated with 0 and $8 \mu \mathrm{mol} / 1$ TBMS1 for $24 \mathrm{~h}$. Clear nuclear fragmentation was observed in the treated A549 cells. Magnification, x3,000.

the Student's t-test, and defined as $\mathrm{p}<0.05$. Analyses were performed using SPSS 11.0 software.

\section{Results}

TBMS1 inhibited A549 cell proliferation. To investigate the growth inhibition effects of TBMS1, the cells were treated with various concentrations of TBMS1 for 24,48 and $72 \mathrm{~h}$. As shown in Fig. 2, TBMS1 had significant growth inhibitory effects on A549 cells in a dose- and time-dependent manner. Concentrations of 4,8 and $12 \mu \mathrm{mol} / 1$ TBMS1 were used in subsequent experiments.
A

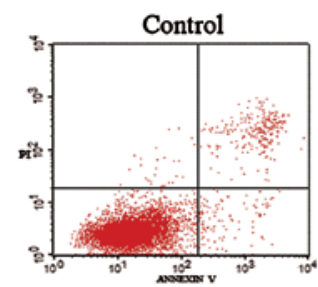

TBMS1 $8 \mu \mathrm{mol} / \mathrm{I}$
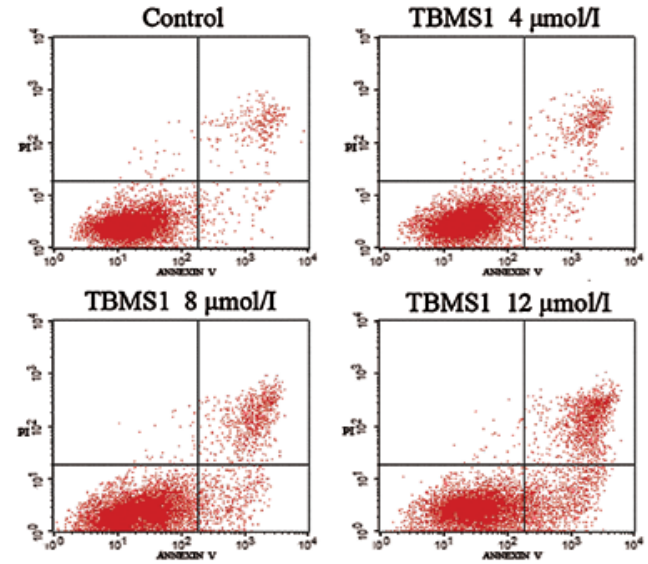

TBMS1 $12 \mu \mathrm{mol} / \mathrm{l}$

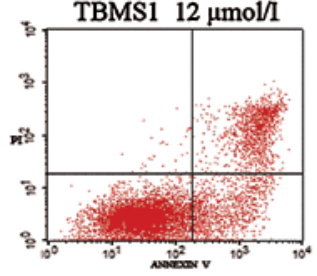

B

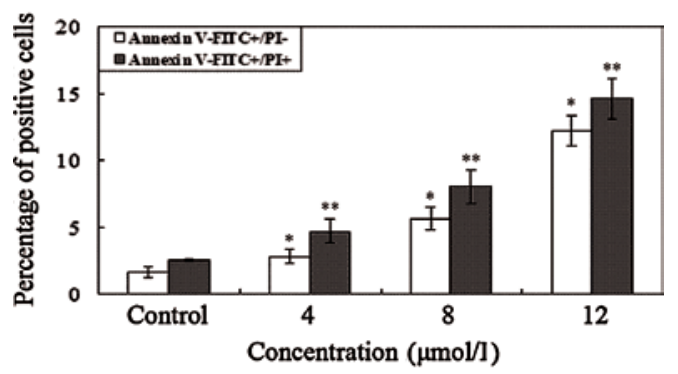

Figure 4. (A) TBMS1-induced apoptosis in A549 cells as assayed by Annexin V/PI staining. A549 cells were treated with $0,4,8$ and $12 \mu \mathrm{mol} / 1$ TBMS1 for $24 \mathrm{~h}$. The cells were then harvested and stained with Annexin V/ PI, and flow cytometric analysis was performed to analyze the extent of apoptosis. (B) Summary of the apoptosis data from the histograms. ${ }^{*} \mathrm{p}<0.05$ vs. the control group (Annexin V-positive); ${ }^{* *} \mathrm{p}<0.05$ vs. the control group (Annexin V- and PI-positive).

TBMS1 induced A549 cell apoptosis. The apoptosis inducing effect of TBMS1 was evaluated by fluorescence microscopy, TEM and Annexin V/PI.

Fluorescence microscopy analysis revealed different morphological alterations in the A549 cells after treatment with TBMS1 (0 and $8 \mu \mathrm{mol} / \mathrm{l})$ for $24 \mathrm{~h}$. As shown in Fig. 3A, clear chromatin condensation and nuclear fragmentation were observed in the treated A549 cells using Hoechst 33342 staining. The results revealed that the A549 cells underwent the morphologic changes typical of apoptosis after treatment with TBMS1 for $24 \mathrm{~h}$.

Intracellular damage caused by TBMS1 $(8 \mu \mathrm{mol} / \mathrm{l})$ for $24 \mathrm{~h}$ was investigated by TEM. The ultrastructure of TBMS1-treated A549 cells revealed TBMS1-induced morphological changes characteristic of apoptosis. As shown in Fig. 3B, clear nuclear fragmentation was found in the treated A549 cells, while the untreated A549 cells exhibited a fairly intact morphology.

The apoptosis inducing effect of TBMS1 was evaluated by Annexin V/PI. As shown in Fig. 4, TBMS1 induced a significant increase in the early and late apoptotic cells at concentrations of 4,8 and $12 \mu \mathrm{mol} / 1$. The total percentages of apoptotic cells (including early and late apoptotic cells) were 7.6, 13.6 and $26.8 \%$, respectively. These results support the finding of TBMS1-induced A549 cell death by apoptosis.

TBMS1 induced expression of apoptosis-related proteins. In order to elucidate the molecular basis of TBMS1-induced apoptosis, the expression levels of $\mathrm{Bcl}-2$, Bax and COX-2 were 


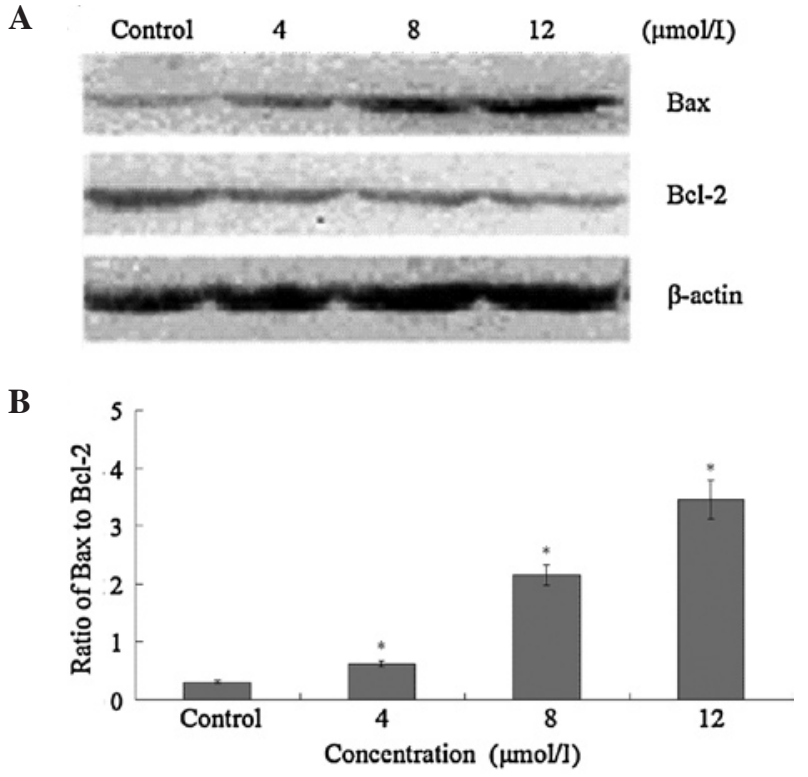

Figure 5. Effect of TBMS1 on the expression of apoptosis-related proteins in A549 cells. (A) A549 cells were treated with $0,4,8$ and $12 \mu \mathrm{mol} / 1$ TBMS1 for $24 \mathrm{~h}$. Western blot analysis was performed using antibodies against Bax, Bcl-2 and $\beta$-actin. (B) Summary of the ratio of Bax to Bcl-2 as demonstrated by histograms. ${ }^{*} \mathrm{p}<0.05$ vs. the control group.

investigated by Western blot analysis. Western blot analysis revealed that TBMS1 treatment led to a decrease in Bcl-2 levels and an increase in Bax levels compared to control cells. The ratio of Bax to Bcl-2 increased as the concentration of TBMS1 increased (Fig. 5). TBMS1 was also observed to decrease the expression of COX-2 in a dose-dependent manner (Fig. 6).

\section{Discussion}

In recent years, the use of plant materials for cancer prevention and therapy has received a great deal of attention owing to their various health benefits and noticeable lack of toxicity and side effects. TBMS1, a triterpenoid saponin whose sugar chains are connected by 3-hydroxy-3-methylglutaric acid to form a unique macrocyclic structure, is the main component in the saponins of Bolbostemma paniculatum (Maxim.) Franquet (Cucurbitaceae) and has been shown to possess numerous pharmacological activities, including anti-inflammatory, anticancer, antiviral and immunosuppressive effects (6-8).

In the present study, we first demonstrated that the proliferation of A549 cells treated with TBMS1 was inhibited in a dose- and time-dependent manner. Flow cytometric analysis revealed that TBMS1 treatment results in an increase in the number of apoptotic cells. Nuclear fragmentation and chromosome condensation were also observed by fluorescent microscopy and TEM. These results suggest that TBMS1-induced apoptosis contributes to the growth inhibition of A549 cells. We also examined the molecular basis of TBMS1-induced apoptosis, and observed the up-regulation of pro-apoptotic Bax protein levels, down-regulation of Bcl-2 protein and COX-2 protein expression.

Members of the Bcl-2 family of proteins are critical regulators of the apoptotic pathway (17). $\mathrm{Bcl}-2$ is an anti-apoptotic regulator, while Bax is a pro-apoptotic regulator
$\mathbf{A}$

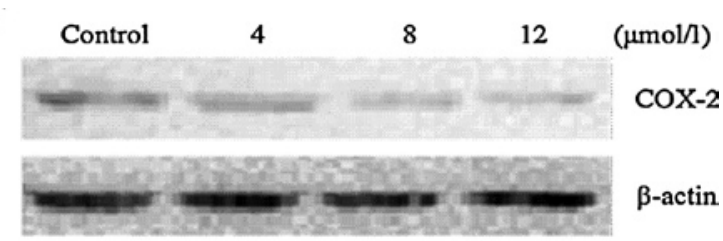

B

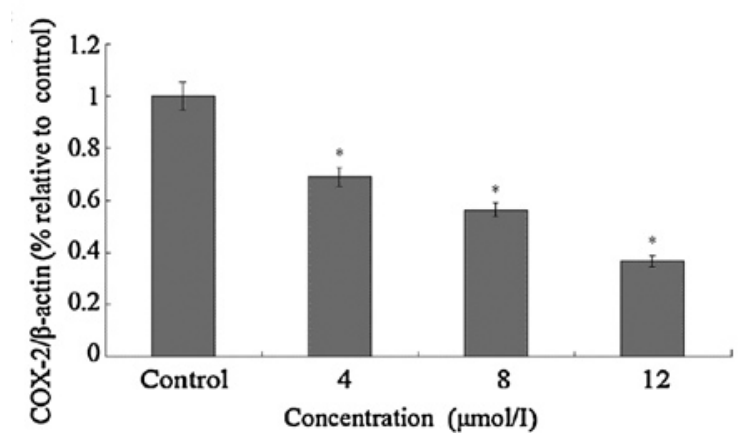

Figure 6. Effect of TBMS1 on the levels of COX-2 protein in A549 cells. (A) A549 cells were treated with $0,4,8$ and $12 \mu \mathrm{mol} / 1 \mathrm{TBMS} 1$ for $24 \mathrm{~h}$. Western blot analysis was performed using antibodies against COX-2 and $\beta$-actin. (B) Summary of the data as demonstrated by histograms. ${ }^{*} \mathrm{p}<0.05$ vs. the control group.

(18). The ratio of Bax to Bcl-2 is critical for the induction of apoptosis, and this ratio determines whether cells will undergo apoptosis (19). Some anti-cancer agents extracted from plants have been found to induce cancer cell apoptosis through the down-regulation of $\mathrm{Bcl}-2$ protein levels and the up-regulation of pro-apoptotic Bax protein expression $(20,21)$. Similarly, in the present study, we found that the expression of Bcl-2 was down-regulated by TBMS1, whereas the Bax expression was up-regulated, leading to up-regulation of the ratio between pro-apoptotic (Bax) and anti-apoptotic (Bcl-2). This may have contributed to the promotion of the apoptotic activity of TBMS1 in the A549 cells.

To further elucidate the mechanisms of the growth inhibitory effect of TBMS1 in human lung cancer cells, we investigated the effects of TBMS1 on COX-2 in A549 cells. COX-2 is a key inducible enzyme that regulates prostaglandin E2 synthesis (22). Various types of cancer, including lung cancer, express high levels of COX-2 (23-29). COX-2 overexpression has been associated with cancer proliferation, invasion, angiogenesis and the inhibition of apoptosis (30-32). In the present study, we found that TBMS1 had a dose-dependent inhibitory effect on the expression of COX-2 in A549 cells. The results revealed that one of the possible pharmacological effects of TBMS1 is the inhibition of the expression of COX-2. It has been reported that $\mathrm{COX}-2$ is one of the upstream factors regulating $\mathrm{Bcl}-2$ expression (33). In our study, TBMS1 decreased the expression of $\mathrm{Bcl}-2$ and increased the ratio of $\mathrm{Bax}$ to $\mathrm{Bcl}-2$ in the A549 cells. Bcl-2/ Bax may be a central pathway leading to TBMS1-induced apoptosis in A549 cells.

In conclusion, we demonstrated that TBMS1 significantly induces apoptosis in A549 cells. This apoptotic response is associated with the up-regulation of the ratio of Bax to Bcl-2. The inhibition of COX-2 may also play an important role in TBMS1-induced apoptosis. Based on these findings, TBMS1 has the potential to be developed as an agent for the management of lung cancer. 


\section{References}

1. Parkin DM, Bray F, Ferlay J and Pisani P: Global cancer statistics, 2002. CA Cancer J Clin 55: 74-108, 2005.

2. Jemal A, Siegel R, Ward E, Murray T, Xu J and Thun M: Cancer statistics, 2008. CA Cancer J Clin 58: 71-96, 2008.

3. Erridge S, Moller H, Price A and Brewster D: International comparisons of survival from lung cancer: pitfalls and warnings. Nat Clin Pract Oncol 4: 570-577, 2007.

4. Fernando JR, Eva ER, José AL and Marta C: Maslinic acid, a natural triterpene from Olea europaea $L$., induces apoptosis in HT29 human colon-cancer cells via the mitochondrial apoptotic pathway. Cancer Lett 273: 44-54, 2009.

5. Li Y, Carl-Magnus B and Lars-Arne H: Resveratrol inhibits proliferation and promotes apoptosis of osteosarcoma cells. Eur J Pharmacol 609: 13-18, 2009.

6. Zhang XH, Sun NX, Guo RX, Xing JL and Liu XN: Efficacy research of tubeimoside against the experimental herpes simplex keratitis. Rec Adv Ophthalmol 22: 373-376, 2002.

7. Yu TX, Ma RD and Yu LJ: Structure-activity relationship of tubeimosides in anti-inflammatory, antitumor, and antitumorpromoting effects. Acta Pharmacologica Sinica 22: 463-468, 2001.

8. Li XH, Wang P and Fu ZC: Effects of Bolbastemmosaponins A on immunologic functions of experimental animals. China Pharm 9: 13, 1998

9. Wang YQ, Yu LJ, Zhu JL and Yang SY: Studies on antitumor action of extracts of Bolbostemma paniculatum (Maxim.) Franquet. Shaanxi Med J 10: 55, 1981.

10. Kong F, Zhu D, Xu R, Fu Z, Zhou L, Iwashita T and Komura H: Structural study of tubeimoside I, a constituent of tubei-mo. Tetrahedron Lett 27: 5765, 1986.

11. Chi-Tai Y, Yerra KR and Chih-Jung Y: Cytotoxic triterpenes from Antrodia camphorata and their mode of action in HT-29 human colon cancer cells. Cancer Lett 285: 73-79, 2009.

12. Edderkaoui M, Odinokova I, Ohno I, Gukovsky I, Go VL, Pandol SJ and Gukovskaya AS: Ellagic acid induces apoptosis through inhibition of nuclear factor kappa B in pancreatic cancer cells. World J Gastroenterol 14: 3672-3680, 2008.

13. Wang F, Ma RD and Yu LJ: Role of mitochondria and mitochondrial cytochrome $\mathrm{c}$ in tubeimoside I-mediated apoptosis of human cervical carcinoma HeLa cell line. Cancer Chemother Pharmacol 57: 389-399, 2006.

14. Liu WY, Zhang WD and Chen HS: New triterpenoid saponins from bulbs of Bolbostemma paniculatum. Planta Med 70 458-464, 2004

15. Liang MJ,Zhang WD and Zhang C: Quantitative determination of the anticancer agent tubeimoside I in rat plasma by liquid chromatography coupled with mass spectrometry. J Chromatogr B 845: 84-89, 2007.

16. Ma RD, Song G and You WB: Anti-microtubule activity of tubeimoside I and its colchicinebinding site of tubulin. Cancer Chemother Pharmacol 62: 559-568, 2008.
17. Oltersdorf T, Elmore SW and Shoemaker AR: An inhibitor of Bcl-2 family proteins induces regression of solid tumors. Nature 435: 677-681, 2005.

18. Metrailler-Ruchonnet I, Pagano A and Carnesecchi S: Bcl-2 protects against hyperoxia-induced apoptosis through inhibition of the mitochondria-dependent pathway. Free Radic Biol Med 42: 1062-1074, 2007.

19. Yao Y, Huang C, Li ZF, Wang AY: Exogenous phosphatidylethanolamine induces apoptosis of human hepatoma HepG2 cells via the bcl-2/bax pathway. World J Gastroenterol 15: 1751-1758, 2009.

20. Jiang TS, Zhou LP and Zhang WL: Effects of sinomenine on proliferation and apoptosis in human lung cancer cell line NCI-H460 in vitro. Mol Med Rep 3: 51-56, 2010.

21. Ren G, Zhao YP, Yang L and Fu CX: Anti-proliferative effect of clitocine from the mushroom Leucopaxillus giganteus on human cervical cancer HeLa cells by inducing apoptosis. Cancer Lett 262: 190-200, 2008.

22. Koehne $\mathrm{CH}$ and Dubois RN: COX-2 inhibition and colorectal cancer. Semin Oncol 31: 12-21, 2004.

23. Masferrer JL, Leahy KM, Koki AT, Zweifel BS, Settle SL, Woerner BM, Edwards DA, Flickinger AG, Moore RJ and Seibert K. Antiangiogenic and antitumor activities of Cyclooxygenase-2 inhibitors. Cancer Res 60: 1306-1311, 2000.

24. Tsubochi H, Nobuyuki S and Hiyama M: Combined analysis of cyclooxygenase- 2 expression with p53 and $\mathrm{Ki}-67$ in nonsmall cell lung cancer. Ann Thorac Surg 82: 1198-1204, 2006.

25. Petkova DK, Clelland C, Ronan J, Pang L, Coulson JM, Lewis S and Knox AJ: Overexpression of cyclooxygenase-2 in non-small cell lung cancer. Respir Med 98: 164-172, 2004.

26. Brown JR and DuBois RN: Cyclooxygenase as a target in lung cancer. Clin Cancer Res 10: 4266-4269, 2004.

27. Brabender J, Park J and Metzger R: Prognostic significance of cyclooxygenase 2 mRNA expression in non-small cell lung cancer. Ann Surg 235: 440-443, 2002.

28. Hasturk S, Kemp B and Kalapurakal SK: Expression of cyclooxygenase-1 and cyclooxygenase-2 in bronchial epithelium and nonsmall cell lung carcinoma. Cancer 94: 1023-1031, 2002.

29. Hosomi Y, Yokose T and Hirose Y: Increased cyclooxygenase 2 (COX-2) expression occurs frequently in precursor lesions of human adenocarcinoma of the lung. Lung Cancer 30: 73-81, 2000.

30. Eibl G, Takata Y and Boros LG: Growth stimulation of COX-2 negative pancreatic cancer by a selective Cox-2 inhibitor. Cancer Res 65: 982-990, 2005.

31. Chun K and Surh Y: Signal transduction pathways regulating cyclooxygenase-2 expression: potential molecular targets for chemo-prevention. Biochem Pharm 68: 1089-1100, 2004.

32. Gasparini G, Longo $\mathrm{R}$ and Sarmiento R: Inhibitors of cyclooxygenase-2: a new class of anticancer agents? Lancet 4: 605-615, 2003.

33. Sheng H, Shao J, Morrow JD, Beauchamp RD and DuBois RN: Modulation of apoptosis and Bcl-2 expression by prostaglandin E2 in human colon cancer cells. Cancer Res 58: 362-366, 1998 